International Journal of Engineering \& Technology, $7(2.34)(2018)$ 69-73
International Journal of Engineering \& Technology
SPC
Website: www.sciencepubco.com/index.php/IJET
Research paper

\title{
Knowledge Management Practice in Private Sector: Building the Way for Saudi Arabia Strategic Growth and Transformation To Knowledge-Based Economy
}

\author{
Abdulrahman Gharamah ${ }^{1}$, Mohamad Fauzan Noordin², Najma Imtiaz Ali ${ }^{3}$, Imtiaz Ali Brohi $^{4}$ \\ Department of Information Systems, Kulliyah of Information Communication and Technology (KICT) \\ *Corresponding author E-mail:Engineer.abdul@yahoo.com
}

\begin{abstract}
The Kingdome of Saudi Arabia (KSA) and its growth objective is to be a major player in the global economy and moving toward a knowledge-based economy. To achieve its objectives, the private sector in various fields in KSA needs to be in line with country's ambitious goal; Knowledge Management (KM) handling and readiness for the foreseen customer demand need to be in line with goals. This study presents a critical review to evaluate existing KM practice in the private sector in Kingdom of Saudi Arabia (KSA) to see the readiness of this sector to play an integral role of knowledge-based economy and support nation's growth strategy. The paper will examine current states in term of how knowledge management is practiced in the country. This paper addressed various aspects of knowledge management ranges from the need of implementing knowledge management systems to the added value by deploying such systems. In addition, the review was discuss if the private sector is heading in the right direction, and coherent with KSA strategic goal by examining a sample of four major firms in private sector. The outcome of the sample reflected that the private sector is harmonized with KSA objective.
\end{abstract}

Keywords: knowledge management; knowledge-based economy; Saudi Arabia; KSA; Saudi Telecom; Saudi Airline

\section{Introduction}

Saudi Arabia is taking major and courage's steps to transform into a knowledge-based economy and consolidate the basis to the information society. Therefore, several mega economic cities are being constructed. They are accompanied by specialized universities and institutes to build the foundation and shift to a knowledgebased economy. Moreover, the country improves its business standards, regulations and existing infrastructure to provide needed services to attract and protect investors. Moreover, business strategy and KM management are being implemented in public sectors such as e-Government. In order to accomplish its target to be a knowledge-based economy, Saudi Arabia implements series of 5-years development plans. One of these plans is ninth development plan [1] which is the recently published plan. The planning emphasizes that the developing and participation of private sector in process of national manpower skill improvement move towards a knowledge economy. Also, it encourages deep partnership between the public and private sectors.

\section{Problem Statement}

Saudi Arabia strategic growth main objective is to be a major player in the global economy and moving toward knowledgebased economy [2]. Therefore, private sectors in various fields need to be in line with country's ambition goal by improving their knowledge management handling and readiness for the foreseen customer demands.

This study was the critical review to evaluate existing knowledge management practice in the private sector in KSA to see the readiness of this sector to play an integral role of the knowledge-based economy and support strategic nation's growth strategy. The research examined current states in term of how knowledge management practised. The study addressed various aspects of KM ranges from the need of implementing knowledge management systems to the added value by deploying such systems. In addition, the review was discussed, if the private sector is heading in the right direction by examining four samples which consider major firms and role player in KSA.:

\subsection{Research Questions}

1. How are Saudi Arabian private industry and service sector practising knowledge management?

2. How Saudi Arabia's firms are in line with Saudi Arabia growth strategy?

3. What are the initiatives taken in private sector?

\subsection{Research Objectives}

1. To determine the extent of knowledge management practice in the Saudi Arabian private industry and service sector.

2. To verify the readiness of Saudi Arabia's firms for Saudi Arabia growth strategy. 
3. To explore private sector's initiatives in knowledge management.

\section{Literature review}

In this section the researchers divided the literature review in to different sections

\subsection{Saudi Arabia Growth Strategy}

Saudi Arabia aspiration is to be part of the global economy major player. King Abdullah Said, "We are keen on making our economy capable of playing a pioneering role in regional and international arenas and meeting the aspirations of its citizens" [2]. Several mega economic cities are currently under construction. They are accompanied by specialized universities such as King Abdullah University of Science and Technology and vocational training centres and institutes to build the foundation and shift to the knowledge-based economy [2]. Prince Bander bin Abdullah said, "We need to support our youth in terms of effective knowledge transfer so that we can compete effectively with businesses in Europe, the US, and Asia" [2].

Saudi Arabia is a member of G-20 which is a forum of the major advance emerging market economic country in the world. KSA implemented G-20 recommendations to improve its economy by including them in its economic and strategic objectives and shift toward knowledge-based economy [3]. The country commenced major steps to diversify its income by and open its markets for private sectors and international investors and looking forward to joining Word Trade Organization (WTO). Dr.Fawaz Al Alamy, Deputy Minister of Commerce and Industry said: "A swift accession to the WTO was important so that we could sit down and debate with our friendly countries and open up to international investment" [2].

\subsection{Ninth Development Plan (2010-2014)}

Saudi Arabia implemented series of 5-years development plans to fulfil its long-term strategic goal to transform into a knowledgebased economy. The ninth development plan is a continuation KSA development approach adopted by KSA in last four decades to combine. The ninth development plan is based on five themes: enhancing and intensifying efforts to improve citizens, development of national manpower and increasing their employment, balanced development among regions of the kingdom structural development and raising the competitiveness of the national economy and national products. The plan, in its brief, emphasis, in its general objectives, developing and participation of private sector in process of national manpower skill improvement to move towards a knowledge-based economy and consolidate the basis of an information society, figure 1 . The planning brief also mentioned, in its major implementation mechanisms, creating an encouraging environment for moving towards a knowledge economy and a gradual transformation towards an information society. Also, it mentioned deepening partnership between the public and private sectors and accelerates privatization processes. Moreover, increasing the contribution of national labour in various developments sectors and provides inclusive and integrated health care [1].

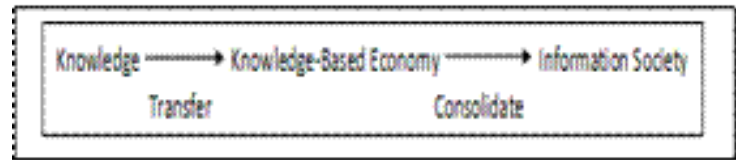

Fig 1: KSA Growth Strategy

\subsection{Knowledge Management in industry and service sectors.}

Several firms invest in technology, process and people which become necessary in order to ensure having desire share in the marketplace. "Globalization and competitions are the main two challenges facing firms who are trying to sustain their success or even to stay in the market" [4].This fast changing environment put Knowledge Management (KM) as essential and integral part of what organizations have to deal with [5]. They set up advanced and complex websites and many knowledge management initiatives to create, maintain and share knowledge internally [4] by accumulating and applying gained knowledge to create an economic value [6]. Braganza and Sharif mentioned that the user who creates knowledge is the one who should maintain it [7]. They incorporate KM activities in their business and operation systems' plans, concentrating chiefly on putting in new innovations in their premises, so as to improve their items and administrations. However, these plans give careful consideration to individuals who are utilizing these innovations and procedures in how these advances are utilized viably and effectively.

The organization understands how to employ KM and what tools and aids to use is essential for successful Knowledge Management [5]. Most organizations do not have a clear vision of knowledge management, its definition and roles in their own organizations, hence continue to lose expertise, experiences and knowledge assets [8]. Moreover, this will contribute to the failure of KM projects and KM initiatives [9]. Companies can become more efficient by transferring what workers know, and then they can develop learning strategies [5]. Knowledge is an important focus strategically, where knowledge is seen as "the most strategically important resource which organizations possess" [10]. This will improve customer service, faster product development and innovations [4].

\section{Knowledge management in Saudi Arabia private sector}

Many studies were conducted to explore knowledge management, knowledge sharing and knowledge-based in Saudi Arabia's private firms [11] [19]. These studies covered various sectors in industries and services such as communications, Information Technology, engineering and consulting services, oil and gas and health and hospital institutions.

This paper focuses on the readiness of private sector to play an integral role in KSA's strategic growth by examining existing KM practice, effective and obstacles and if private sector KM heading to the right direction in the line of the ninth development plan. A sample of four firms will be studied and investigated in various industry and services organizations. These businesses are health and hospital institution, Saudi Aramco, Saudi Airlines and Saudi Telecom.

\subsection{Health and Hospital Institutions}

Saudi Arabia's Medical Health Care (MHC) is challenged to improve patients' satisfaction and reduce medical error which reached to 670 cases in 2009 alone. This is a very alarming number [13]. Although the need for Strategic Healthcare DecisionSupport Services (SHDS) become necessary, several technical, organizational, cultural, financial and human nature obstacles facing medical fraternity network. SHDS envisioned support to collect, process, store and share knowledge. Furthermore, establish organization learning process [11]. Figure 2 shows an overview of Saudi Arabia hospital current health care system. Saudi 
Health Care System has two branches public and private sectors. Ministry of Health $(\mathrm{MOH})$ concerned of finance public hospitals provision and needs. This includes various services such as school health units, referral hospitals and teaching hospitals. MOH provides 605 of health care services countrywide. These agencies work under full-time inspection and investigation by the government agencies [20].

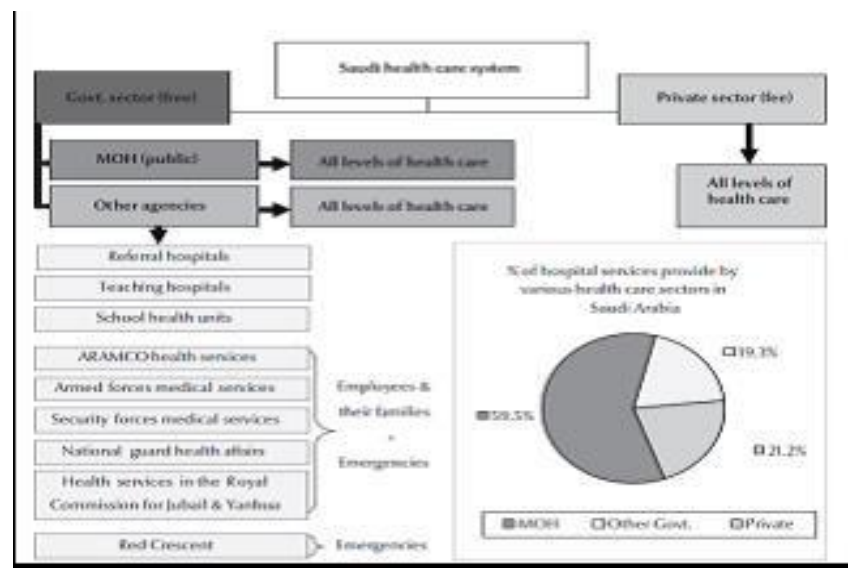

Fig 2: Current Saudi Arabia Health Care System

\subsection{Oil and Gas (Saudi Aramco)}

Saudi Aramco is not only the world's top exporter of crude oil and natural gas liquids, it is also the Saudi Arabia economy backbone where it generates more than $85 \%$ of Saudi Arabia exports and more than $90 \%$ of government revenue [21]. Saudi Aramco supports the KSA's economic development growth by organizing aspiring and comprehensive projects on a commercial basis [22]. Ali I. Al-Naimi Minister of Petroleum and Mineral Resources Chairman of the Board of Directors said: "as our country continues to diversify its economy, new business and employment opportunities present themselves" he continued and said, "Saudi Aramco is at the forefront by driving economic growth in the Kingdom" [22]. Khalid A. Al-Falih President and Chief Executive Officer of Saudi Aramco stated "we will ramp up our support of entrepreneurs and small- and medium-sized businesses through funding and incubation programs, support the government in its ambitious National Energy Strategy to improve energy efficiency and economic value creation, increase our investments in training and development" [22].

The company commenced a new approach to be a better organization by transforming its corporate culture and deploying 3Ts: Talent, Teams and Technology concepts to support its business strategies [23].

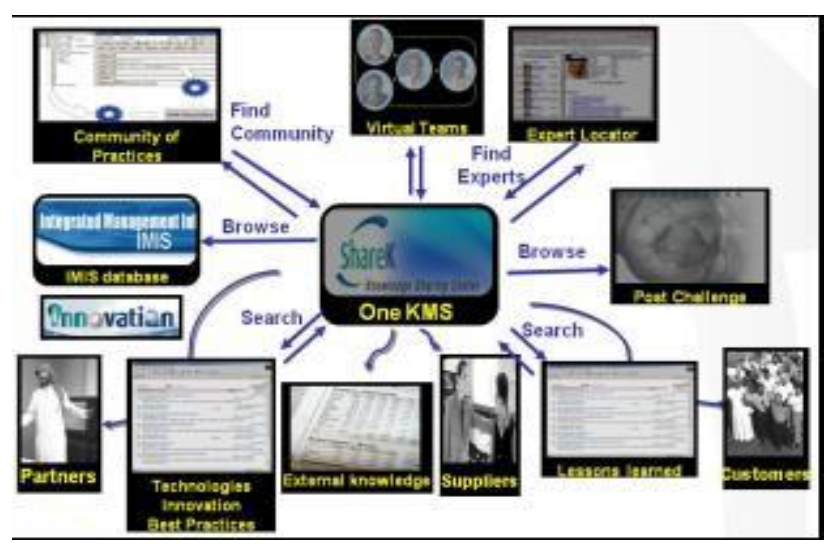

Fig 3: Various functionalities in many KM components

\subsection{Saudi Airlines (Saudia)}

Saudi Airlines (Saudia) is the official carrier of Saudi Arabia. Saudia is one of the leading airline firms where it operates more than 139 destinations worldwide [24]. Saudia implemented knowledge management solution called Holistic OperationBased Knowledge Management (OBKM). The objective for its $\mathrm{KM}$ is to assist the technical and sales staff at the airlines to form a closed social network [18]. The solution is in-house development built on top of ERP SAP application SAP NetWeaver portal component. This is in order to automate tasks to help in forecasting, planning and seat booking. Also to store and archive knowledge artefacts and help in their retrieval. It accesses many databases. Figure 4 shows OBKM framework which has three Aspects leadership, process management and people management Aspects [14] Leadership Aspect is to enable organization leader to enforced knowledge sharing culture. Process Management Aspect is to ensure better process through the organization policy, procedure and work instructions, and monitoring. People management Aspect is to highlight knowledge sharing a culture that influences OBKM success such as teamwork and mentoring. OBKM expedited problem solutions that take more than three days to be solved and understood in few hours. This enabled Saudia to reduce the maintenance repair time by $8 \%$, a substantial gain for an industry where normal margins are often less than 3\% [18].

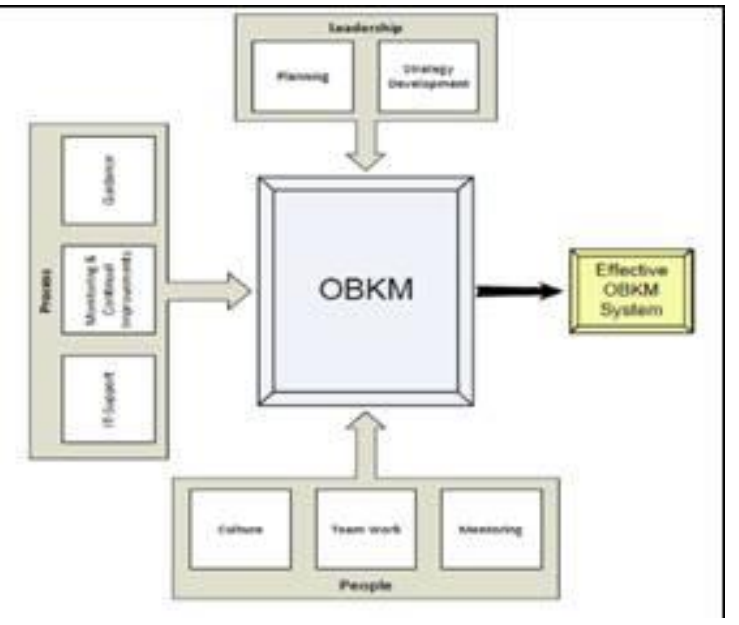

Fig 4: Saudia OBKM KM framework

\subsection{Saudi Telecom Company (STC)}

Saudi Telecom Company (STC) is the first communication operator in Saudi Arabia. It was transformed from public sector to private sector in 2002. STC is the largest telecommunication carrier in KSA and provides mobiles, Internet and landlines services.

Knowledge Exchange is STC KM solution. It was implemented to support STC LEAD initiative. The LEAD program was created to assist STC to increase its international operations, customer satisfaction and offer its convergence solutions to all its centres worldwide [16]. KM was initially designed to help technical teams and sales personnel to share problems and solutions. $\mathrm{KM}$ is to be used by STC employee across its divisions. It has three branches: $\mathrm{KM}$ branch, research and consultation branch and policy and procedure branch. The KM enables users to upload and share their reports and experience. Customer services were improved and frontline is able to solve customer complaints [19]. KM solution provided advice to management for future feedback for future service and market planning. Although a large number of supervisors and mid-level managers accepted and utilized KM solution to carry out their functions and roles with greater efficiency and customer satisfaction, there was still less participation from individuals: technicians and operators. Figure 5 demonstrates STC KM framework concept [16]. 


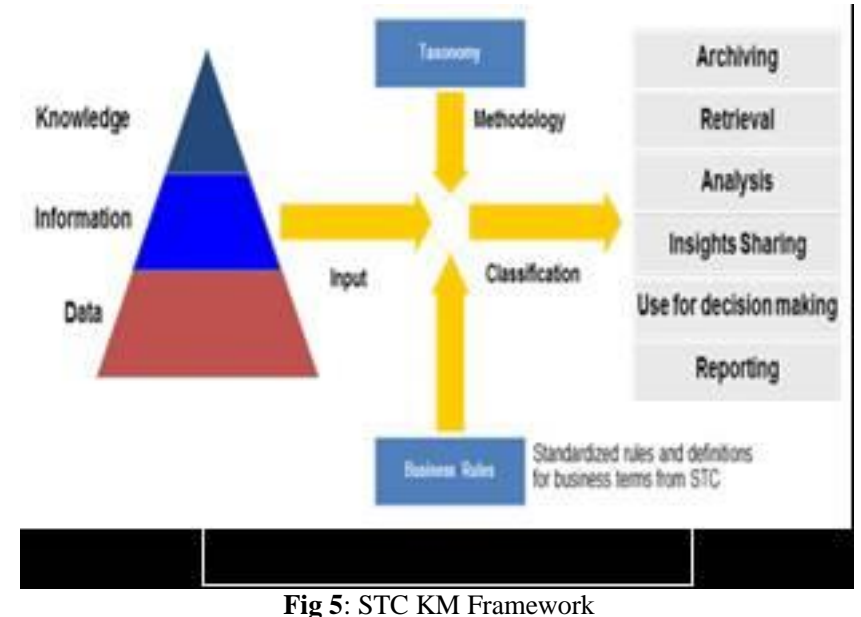

Fig 5: STC KM Framework

\section{Health and Hospital Institutions}

In this paper, the readiness for the private sector in various private sector fields is being addressed to know if private sectors are complementing the public sector and moving in the right directions toward nation's knowledge-based economy. Four leader firms were explored and reviewed in term of how they practised their knowledge management, Used KM solution, its effectiveness and value-added, benefit and ultimately a contribution to nation knowledge-based economy. The four leader firms were selected, private hospitals, Saudi Aramco, Saudi Airlines and Saudi Telecom.

\subsection{Health and Hospital Institution (Private Hospitals)}

Saudi Arabia's private Medical Health Care (MHC) needs Strategic Healthcare Decision-Support Services (SHDS) to improve their services and patients' satisfaction. Although there is a clear vision of how to improve MHC, still there are several obstacles to be addressed in order to successful SHDS. According to this review, most CSF are not there to start implementation. One of the reasons is the $\mathrm{MOH}$ focus support to the public sector. Another reason is the knowledge is not shared because there is no mechanism or tool enabler. Hospitals work in isolated islands and no organization that combine them together and exchange experience and lesson learned. This explains the high error fatalities.

\subsection{Saudi Aramco}

Saudi Aramco leadership has a clear vision of what needs to be done to complement country strategic goal. This is can be seen in the on comments made by high company officers. Sharee is the customized version of Microsoft SharePoint used by the company to satisfy its needs. Saudi Aramco is transforming its culture to be knowledge-based organization and ultimately information society. This is fully in line with KSA growth strategy and ninth development plan. The company requires additional work in its structure and measurement tool to improve Share from the only portal with link capabilities to fully Discussion Support System (DSS) with workflow and measurement.

\subsection{Saudi Airlines}

Saudi Airlines implemented knowledge management in-house is a SAP NetWeaver portal component on top of SAP ERP solution following Operation-Based Knowledge Management (OBKM) framework. This solution assists technical and sales staff at the airlines to form a closed social network by automating tasks in forecasting, planning and seat booking. Also, storing and archiving knowledge artefacts and help in their retrieval. The solution also has various aspects to improve leadership, process and knowledge sharing. It has DSS capabilities and monitoring and measurement tools. This is fully in line with KSA growth strategy and ninth development plan.

\subsection{Saudi Telecom}

Saudi Telecom Company (STC) implemented Knowledge management system called Knowledge Exchange to support STC LEAD program. Although the system is high accepted by middle management and low management, however, it is not fully acknowledged by individuals: employee and technicians. It is clear that there is intelligent in this system where it has ability to do forecast and planning. It enables users to sharing.

\section{Interpretation}

There was no precise measurements mentioned and the company is consistent with KSA growth strategy and ninth development plan. Table 1 show relationships between Firms' Critical Success Factors and KSA Growth Strategy and ninth development plan.

Table 1: Critical Success Factors and KSA Growth Strategy and ninth development plan Matrix

\begin{tabular}{|l|l|l|l|l|l|l|l|l|l|l|}
\hline & \multicolumn{4}{|l|}{ Critical Success Factors (CSF) } & \multicolumn{3}{l|}{$\begin{array}{l}\text { Saudi Arabia Growth Strategy and Ninth Development Plan } \\
\text { Elements of Knowledge-based Economy }\end{array}$} \\
\hline Firm & Leadership & Culture & $\begin{array}{l}\text { Organization } \\
\text { Structure }\end{array}$ & IT & Measurements & Employment & Skill & partnership & $\begin{array}{l}\text { Knowledge } \\
\text { Economy }\end{array}$ & $\begin{array}{l}\text { Information } \\
\text { Society }\end{array}$ \\
\hline $\begin{array}{l}\text { Health \& } \\
\text { Hospital } \\
\text { Institution }\end{array}$ & No & No & No & No & No & Yes & No & No \\
\hline $\begin{array}{l}\text { Saudi } \\
\text { Aramco }\end{array}$ & Yes & Yes & Yes & Yes & No & Yes & Yes & Yes & Yes \\
\hline $\begin{array}{l}\text { Saudi } \\
\text { Airlines }\end{array}$ & Yes & Yes & Yes & Yes & Yes & Yes & Yes & No & Yes \\
\hline $\begin{array}{l}\text { Saudi } \\
\text { Telecom }\end{array}$ & Yes & No & Yes & Yes & Yes & Yes & Yes & No & Yes & No \\
\hline
\end{tabular}

\section{Conclusion}

The private sector is definitely in line with Saudi Arabia strategic growth knowledge-based economy and tactical development plans as most firms except private hospitals has both CSF and elements of Knowledge-based economy.

\section{References}

[1] Ministry of Economy and Planning, "Brief report on the ninth development plan 2010-2014," vol. 1431/32-14, pp. 2-85, 2014.

[2] S. Arabia, T. H. Mosques, and K. Fahd, "SAUDI Mastering the Challenges of Globalization," 2014 
[3] "Comprehensive Growth Strategy: Kingdom of Saudi Arabia," 2015.

[4] A. Braganza, "Knowledge management during radical change: applying a process oriented approach," Int. J. Entrep. Innov. Manag., vol. 2, no. 4, pp. 294-307, 2002.

[5] K. Ichijo and I. Nonaka, Knowledge creation and management: New challenges for managers. 2006.

[6] M. Sarabia, "Knowledge leadership cycles: an approach from Nonaka's viewpoint,” J. Knowl. Manag., 2007.

[7] A. Braganza and A. Sharif, "The knowledge management kaleidoscope: Keeping stakeholders and their expectations in focus," 2010.

[8] M. Goswami and A. Goswami, "Integrated Framework for Implementing Knowledge Management in Contemporary Organizations," Glob. J., 2013.

[9] A. Braganza, "Death of a knowledge project," 2003.

[10] R. M. Grant, "Prospering in Dynamically-Competitive Environments: Organizational Capability as Knowledge Integration," Organ. Sci., vol. 7, no. 4, pp. 375-387, 1996.

[11] S. Abidi, "Knowledge management in healthcare: towards 'knowledge-driven'decision-support services,' Int. J. Med. Inform., 2001.

[12] M. Al-Shammari and H. Al-Musharraf, "KNOWLEDGE SHARING CULTURE IN A RESEARCH AND DEVELOPMENT DEPARTMENT OF AN ARABIAN GULF COMPANY," ijecm.co.uk.

[13] T. A. Business and O. C. Proceedings, "Barriers to Implementation of Knowledge Management in Hospital Institutions in Saudi Arabia,” Asian Bus Manag Conf, vol. 5, no. 1, pp. 47-76, 2012.

[14] R. Zawawi, H. Akpolat, and R. Bagia, "Operations-based knowledge management," Oper. Manag., 2011.

[15] L. Riz, "Comparative analysis of knowledge management in different parts of the world," Life Sci. J., 2014.

[16] I. El Emary, H. Alsereihy, and A. Alyoubi, "Towards Improving the performance of STC Saudi using knowledge management strategies," Middle-East J. Sci. Res., 2012.

[17] H. Magd and S. Hamza, "A Proposed Knowledge Management System in SOFCON: Saudi Arabia Perspectives," Nang Yan Bus. J., 2012.

[18] H. Alsereihy, B. Alyoubi, and I. El-Emary, "Effectiveness of Knowledge Management Strategies on Business Organizations in KSA: Critical Reviewing Study," Middle-East J. Sci. Res., 2012.

[19] K. AlRowaily and A. Alsadhan, "Integration of Knowledge Management System in Telecom-munication: A Case Study of Saudi Telecom," IJCSNS, 2012.

[20] T. A. Business and O. C. Proceedings, "Barriers to Implementation of Knowledge Management in Hospital Institutions in Saudi Arabia," vol. 5, no. 1, pp. 47-76, 2012.

[21] E. Woertz, "The domestic challenges in the Saudi energy market and their regional and geopolitical implecations," no. November, pp. 2010-2012, 2013.

[22] A. I. Al-naimi, "outcomes for the people of Saudi Arabia," 2012.

[23] S. Khursani, O. Bazuhair, and M. Khan, "Strategy for rapid transformation of Saudi Arabia by leveraging intellectual capital and knowledge management," Saudi Aramco J. Technol., 2011.

[24] A. Report, "Driven by theory," Nat. Nanotechnol., vol. 10, no. 11, pp. 909-909, 2015.

[25] A. Braganza, "Knowledge management during radical change: applying a process oriented approach," Int. J. Entrep. Innov. Manag., vol. 2, no. 4, pp. 294-307, 2002.

[26] K. Ichijo and I. Nonaka, Knowledge creation and management: New challenges for managers. 2006.

[27] M. Sarabia, "Knowledge leadership cycles: an approach from Nonaka's viewpoint,” J. Knowl. Manag., 2007.

[28] P. Schütt, "The post-Nonaka knowledge management," J. UCS, 2003.

[29] M. Rahman, "A Holistic and Institutional Analysis of Islamic Education," The American Journal of Islamic Social Sciences, vol. 11, no. 4. pp. 519-531, 1994.

[30] R. M. Grant, "Prospering in Dynamically-Competitive Environments: Organizational Capability as Knowledge Integration," Organ. Sci., vol. 7, no. 4, pp. 375-387, 1996.

[31] M. Goswami and A. Goswami, "Integrated Framework for Implementing Knowledge Management in Contemporary Organizations," Glob. J., 2013.

[32] E. Woertz, "The domestic challenges in the Saudi energy market and their regional and geopolitical implecations," no. November, pp. 2010-2012, 2013.
[33] J. Creswell, A concise introduction to mixed methods research. 2014.

[34] M. F. Noordin. and International Islamic University Malaysia., ICT and Islam, First edition. Kuala Lumpur: IIUM Press, 2009.

[35] P. Rasmussen and P. Nielsen, "Knowledge management in the firm: concepts and issues," Int. J. Manpow., 2011.

[36] W. Zheng, B. Yang, and G. N. McLean, "Linking organizational culture, structure, strategy, and organizational effectiveness: Mediating role of knowledge management," J. Bus. Res., vol. 63, no. 7, pp. 763-771, 2010. 